\title{
Playing with surveillance: The design of a Article mock RFID-based identification infrastructure for public engagement
}

\section{Karen Louise Smith}

$\underline{\text { karen.louise.smith@,utoronto.ca }}$
Brenda McPhail

brenda.mcphail@utoronto.ca
Joseph Ferenbok

joseph.ferenbok@utoronto.ca

\section{Alex Tichine}

alex.tichine@utoronto.ca
Andrew Clement

All: University of Toronto, Canada.

andrew.clement@utoronto.ca

\begin{abstract}
In many jurisdictions around the globe, governments are developing ID schemes based on radio frequency identification (RFID) and biometric technologies. In Canada, four provinces recently implemented RFID based 'enhanced' drivers licences (EDL) in response to the United States' Western Hemisphere Travel Initiative (WHTI), which requires all persons entering the United States to present a valid passport or alternative 'secure' document to prove their identity and citizenship.

As researchers, we were closely involved in following the EDL policy development process. It became evident, as we attended legislative hearings, that parliamentarians needed clarifications to understand how the RFID identification scheme would function in practice. This project began with the goal of designing prototypes to demonstrate security and civil liberty concerns with a new RFID-based identification (ID) scheme in Canada. Influenced by participatory design and probe approaches to technology design, we built and tested mock infrastructures of RFID-based identification systems including low fidelity paper prototypes, and high fidelity prototypes using RFID-chipped cards, a database, antenna and reader. We also worked closely with civil society organizations to run public engagement activities.

This paper reports on our attempts to create spaces for 'playful' engagement with RFID-based ID scheme technology at a time of 'serious' policy deliberations. Designed in the spirit of serious play, our mock ID infrastructures make the security and civil liberties challenges inherent in the proposed combination of ID cards and databases more visible, while demonstrating how such ID schemes work. At this point, we see future promise in the design and use of mock ID infrastructure for public engagement during relevant policy deliberations about ID schemes and databases which contain personal information.
\end{abstract}

\section{Introduction}

ID cards are never about the cards; they are always about the databases behind the cards (Schneier 2009).

There is no secret to safety (motto, Total Transparency Solutions ${ }^{\mathrm{TM}}$ ).

Smith, Karen Louise, Brenda McPhail, Joseph Ferenbok, Alex Tichine and Andrew Clement. 2011. Playing with surveillance: The design of a mock RFID-based identification infrastructure for public engagement. Surveillance \& Society 9(1/2): 149-166. http://www.surveillance-and-society.org | ISSN: 1477-7487

(C) The authors, 2011 | Licensed to the Surveillance Studies Network under a Creative Commons Attribution Non-Commercial No Derivatives license. 
When 'security guru' Bruce Schneier was introduced as keynote speaker of the University of Toronto's Information, Privacy and Security Institute 2009 Research Symposium, the audience was forewarned about some disturbing features of his personal life. Thanks to the database developed by Total Transparency Solutions ${ }^{T M}{ }_{1}$ who were providing their total registration and protection solution services for the event, some surprising details about Schneier's personal history and political sympathies were revealed. As he walked into the lecture theatre, the RFID antenna positioned by the door read the chip in his ID card, triggering the display of his stored profile on the screen at the front of the room. The audience could read his nine previous addresses, clearly highlighting Schneier's itinerant tendencies, and suggesting an unstable lifestyle inconsistent with his positions of authority and trust. His on-the-record history of donations to the Democratic Congressional Campaign Committee and other similar charitable organisations alerted the audience to his liberal sympathies, appropriately allowing those listening to examine his comments for political bias, while his supplemental profile picture, wearing a keffiyeh, demonstrated both his Arab sympathies and a proclivity to disguise his identity. Without the careful collection of this accurate information compiled from the web as part of the Total Transparency Solutions ${ }^{T M}$ identification database and linked to the unique identifier on his RFID chipped ID card, the group assembled that day to listen to Mr. Schneier speak would have lacked crucial information regarding his true character and identity (see Figure 1).

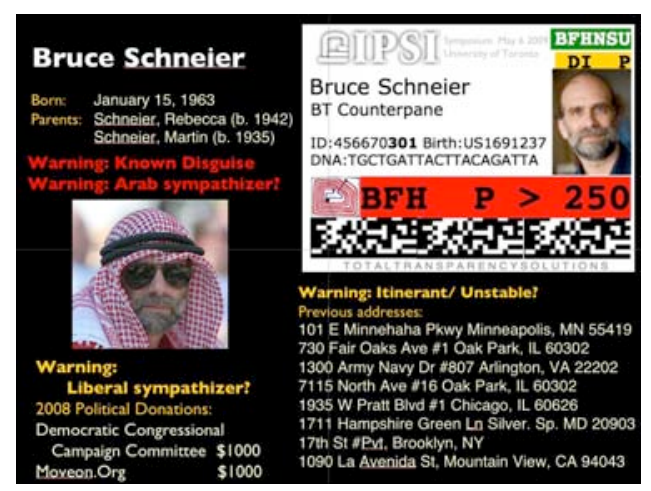

Figure 1: Bruce Schneier mock profile linked to RFID infrastructure ${ }^{2}$

There was such a research symposium, Bruce Schneier did present the keynote speech, and these details of his life (with his knowledge and to his amusement) were 'revealed' to the audience (see Schneier 2009). The presentation of Schneier's mock profile was deployed by the Performing Identities Research group as part of a research project affiliated with The New Transparency: Surveillance and Social Sorting research collaboration. ${ }^{3}$ The goal of the presentation, and of designing the technological infrastructure behind it, is to make the hidden capacities of ID systems and surveillant infrastructures visible, and to develop ways to engage citizens in the sometimes dull and technical debates that occur around the implementation of new identification schemes. Schneier's profile was part of a playful demonstration of the way that RFIDenabled identification documents linked to databases might work - either as part of an official process or as a result of surreptitious information collection. In a firmly tongue-in-cheek manner, which had some audience members laughing and others a little confused, the research team sought to make the demonstration memorable, engaging, and provocative, while also presenting an authentic example of these

\footnotetext{
${ }^{1}$ In using the moniker Total Transparency Solutions ${ }^{\mathrm{TM}}$ we acknowledge that we have appropriated the 'TM' symbol for parody. Organizations such as ${ }^{\circledR}{ }^{\mathrm{TM}}$ ark (pronounced art mark) have previously used these branding symbols as part of their identity when spoofing the World Trade Organization's (WTO's) website at www.gatt.org in advance of the Seattle meetings for the WTO. ${ }^{\circledR}{ }^{\mathrm{TM}}$ mark transferred the www.gatt.org domain to the Yes Men in 2000 (Samuel 2004).

${ }^{2}$ Images and data used with permission of Bruce Schneier. Photo credits: upper right facial image: Geoffrey Stone; lower left facial image: anonymous photographer at the Winnipeg Folk Festival.

${ }^{3}$ See: http://www.sscqueens.org/projects/the-new-transparency/about
} 
technologies in use, using the same equipment deployed in real-world implementations of this type of system. A concern over the potential lack of public and even governmental understanding of ID technology lies at the heart of our research.

In Canada, new ID schemes including cards and databases have recently been considered and sometimes implemented in the security-oriented policy climate which follows from the World Trade Center attacks. The United States' Western Hemisphere Travel Initiative (WHTI), part of the US Intelligence Reform and Terrorism Prevention Act (2004), requires all persons entering the United States to present a valid passport or an approved, alternative 'secure' document to prove their identity and citizenship. Prior to the June 2009 deadline set by the US for the implementation of this requirement, seven Canadian provinces considered developing EDLs (Enhanced Driver's Licences) and EICs (Enhanced Identification Cards) to serve as an authorized passport alternative for land border crossings. These are cards equipped with radio frequency identification (RFID) chips and citizenship information. Four Canadian provinces (British Columbia, Manitoba, Ontario and Quebec) have implemented EDLs or EICs thus far. However, there was relatively little public debate about the merits or potential disadvantages of this kind of ID document, or about the infrastructure that would have to be developed to support it. Since, as Lyon notes, categorizing citizens, and by extension non-citizens, through ID cards and backend databases is a kind of 'social sorting' with potentially significant social implications (2009), the research reported here attempts to encourage public debate and disseminate accessible information about such systems in an engaging manner.

The ID cards are the most visible aspect of EDL programs, but, like the tip of an iceberg, the ID cards citizens hold in their wallets provide very little sense of the massive infrastructure beneath the surface that is necessary for their functioning. And without a sense of what lies beneath, it is difficult to fully comprehend the surveillance and privacy risks of such systems. The idea that the databases behind identification (ID) cards present security and privacy risks is a common understanding among experts in the field. Governments typically maintain the large-scale databases which act as the backend to public identification schemes such as driver's licences, and this does not change with the introduction of EDLs. Citizens in western democratic nations may have a reasonable expectation that governments will protect their personal information, an expectation that extends to ID databases. However, the policies and practices involved in the creation and maintenance of such databases are rarely available for the public to scrutinize. In the case of EDLs/EICs, in addition to the RFID technology, biometric face recognition technology is used to screen all enhanced ID applicants against the complete photo database to attempt to prevent the issuing of duplicate or fraudulent IDs (McPhail et al. 2009). In addition, database information is shared with American border officials when the EDL is used as proof of citizenship at a border crossing. The potential privacy risks in both of these policies associated with the EDL database illustrate the importance of citizens' understanding not just how the cards work, but what lies beneath and how that works too.

Within the context of EDL/EIC policy development in the province of Ontario, and Canada more broadly, this paper explores a playful approach to engage the public and help them to better understand the implications of RFID-enabled ID schemes. We recognize that information infrastructures are often seen as 'boring' (Star 2002), making it difficult to engage the public imagination when talking about largely invisible and inscrutable technologies, so we actively attempt to make our prototypes engaging and relevant. As a part of our research initiative, we developed a mock ID infrastructure including simulated EDLs and a database. At events such as public forums and research presentations, we use commercially available RFID-reading equipment (such as an antenna and handheld reader), the same type of equipment the US government uses at border crossings, to demonstrate how these systems work. In this manner, we encourage serious play with infrastructure. 
This paper presents the theoretical and policy contexts which inform our work. We begin by exploring the composition of ID schemes, their relation to surveillance, and our conceptualization of design intervention opportunities and limitations in a broad sense. Next, we explore formative playful influences of our design and provide examples of influential play from the literature. Finally we discuss our design motivations, design process and implementation reflections. Overall, this paper argues that playful approaches to the design and use of ID infrastructures can be used as a research strategy by Surveillance Studies scholars. The controversial aspects of ID schemes can be demonstrated through mock infrastructure to foster a better understanding of the surveillance and privacy risks. In the future, we believe that mock ID infrastructures may be useful during ID policy debates and might potentially be more effectively deployed during policy deliberations.

\section{ID schemes, surveillance and black boxes}

Schneier (2003) notes that national ID card schemes and related systems such as driver's licences involve: 1) 'a physical card' which contains personal information in text or encoded form (i.e. in a barcode, chip, etc.); 2) 'a database somewhere of card numbers' linking them to representations of identities to allow authorized persons to 'verify cards'; 3 ) 'a system for checking the card data against the database' such as a computer; and 4) 'some sort of registration procedure' to allow for issuing cards and making additions to the database (p. 204). In the case of the EDL/EIC cards, these elements are all in use at sites such as USCanada border crossings or government issuing offices where they are used during application processes.

But of course, ID cards are not just used in official contexts; they are also regularly pulled out of pockets or purses for use in a variety of settings. Surveillance Studies helps to critically interrogate the development and use of ID schemes in context. A number of scholars have provided foundational works that look at the development of identity documents and other tokens. Torpey (2000) and Lloyd (2003) both examine the development of the passport as a mechanism of citizenship, entitlement and surveillance. Lyon (2009) in particular has focused on how ID card schemes have been implemented as mechanisms of surveillance and social sorting. Lyon asks us to consider that 'the surveillance capacities of new digital systems represent a quantum leap compared with old paper file systems' (p. 5) and encourages us to think of the 'uncertainties and anxieties' (p. 13) of sorting citizens in the post $9 / 11$ era where enhanced technologies are in use. Surveillance Studies scholars also provide analytical frameworks for thinking about bias in ID schemes. For example, Friedmann and Nissenbaum (1996) discuss frameworks to understand bias in computer systems, while Introna and Wood (2004) provide insights for understanding algorithmic surveillance.

Science and technology studies (STS) is an interdisciplinary field that offers many helpful and complementary insights to Surveillance Studies to guide the design of mock ID infrastructure. Infrastructure is a key site of study for STS scholars who wish to explore the co-construction of end-users and technologies (see for example: Bowker and Star 1999; Brown 2001; Summerton 2004). Infrastructure is also often treated as a kind of black box (Pinch and Bijker 1984; Winner 1993). Combining the Surveillance Studies focus on identification systems with the STS emphasis on socio-technical dynamics, we are particularly interested in considering the policy development of the EDLs/EICs as a period when the 'black box' is open (or at least partially open, enough to allow for intervention) and where there is still some interpretive flexibility while a technology is being legislated for implementation and is not yet stabilized. ${ }^{4}$ At the same time, we recognize that certain decisions about EDL/EIC infrastructure in Ontario are unlikely to be changed (e.g., Homeland Security's requirement to use RFID EPC Gen 2 technology proved to be largely unchallengeable in Ontario's legislative process).

\footnotetext{
${ }^{4}$ Interpretive flexibility and stabilization are key concepts from social construction of technology scholars see (Pinch and Bijker 1984).
} 
Playful Influences / Influential play

When this project began with the idea of adopting a playful design approach to serious infrastructures, the primary formative influences were the playful and iterative prototyping approaches used in participatory design, and the experiential engagement of design probes as characterized by Gaver, both of which will be described below. However, we were also influenced to varying degrees by other approaches which might loosely be affiliated with the concept of 'serious play' and by a body of artistic work which specifically comments on and engages with surveillance infrastructures as an issue.

\section{Serious Play}

The term 'serious play' is used in various contexts. In the education field, it often refers to the design or use of playful activities intended to integrate learning with fun; these may range from physical games to computer games. In education, the game space for serious play is used to promote learning, development or change (Ritterfield, Cody and Vorderer 2009). When discussed in conjunction with military contexts, war game simulations can involve the highest levels of political and military power (Schrage 2000) or military training via video games (Orvis et al. 2010). The term has also gained currency in the organizational literature, where authors such as Schrage use it to describe an approach to innovation that uses models or prototypes to explore the realistic possibilities of new products. Similarly, Lego blocks have been used in game-like activities to assist in designing new organizational strategies, services or products (Lego n.d.). Although the goals of serious play and the ways in which it is implemented vary as widely as one might expect given the range of fields in which it is used, there are some common elements which our project shares. Serious play is about experience and insight, about allowing understanding to emerge by taking a playful approach to a serious concern.

\section{Surveillance and Art}

Although the concept of serious play as a term has become linked with games and gaming, the idea of playful engagement with sociopolitical issues and concepts also has a longstanding tradition in the art community. Surveillance Studies scholars may already be familiar with how playfulness and art can intersect. Albrechtslund and Dubbeld (2005) suggest that art projects offer one playful opportunity to communicate with the public about surveillance issues. Both guerilla art and juried installations have been used to express critical messages from Surveillance Studies discourse. For example, through the Surveillance Camera Players (SCP), Michael Carter (1995) and Bill Brown (1996) called for individuals to launch dramatic performances in front of security cameras in New York City. An original intention of the SCP was to subvert the purpose of the surveillance infrastructure. Similarly, the interactive media collective Blast Theory created a game called 'Can You See Me Now?' where individuals run through a city while GPS equipment transmits their positions to a virtual map (Albrechtslund and Dubbeld 2005). In both cases, the artists leveraged what may be thought of as surveillance infrastructures for fun and critique. While making no claims to be artists ourselves, we pursued similar aims in our design exploration, albeit with a more explicit policy intervention focus.

During the period of our prototype development we interacted with a visual artist, Dave Kemp, who in a parallel project probed peoples' willingness to publicly expose personal information held on their ID cards. Kemp solicited identity cards from individuals willing to exhibit 'anything that connects to a database' (Allen, Robertson and Smith 2010, 22). The result was the Data Collection photographic installation at the curated exhibition, 'Sorting Daemons: Art, Surveillance Regimes and Social Control' (2010). Occupying a large wall of the art gallery, Kemp's project presented ID portraits of over 100 individuals, including co-authors Clement, Ferenbok and Smith (see Figure 2). ${ }^{5}$

\footnotetext{
5 Several other artists engaged with surveillance infrastructures also participated in this exhibition, affiliated with the New Transparency research collaboration. We note that artist David Rokeby, is well known for his Sorting Daemon installation (2003), in which he explored the automation of social sorting during the 'war on terrorism'.
} 


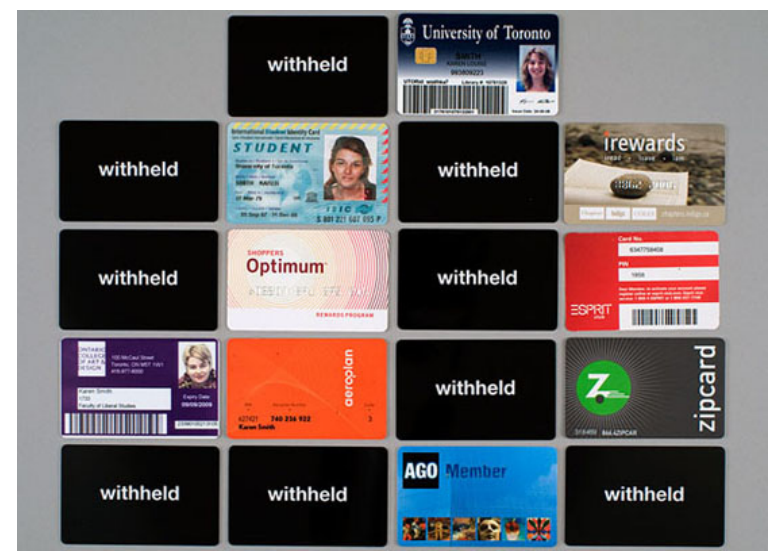

Figure 2: Data Collection (2010); ID portrait of Karen Smith taken by Dave Kemp

\section{Participatory design}

Turning from broad influences of serious play and art that plays with surveillance, we now consider the design traditions that were formative for us: participatory design and probes. Participatory design (PD) is an approach to systems development which emerged in Scandinavia in the 1970s (Bjerknes and Bratteteig 1995; Clement and Besselaar 1993). It began with computer scientists working with trade unionists to design systems that promoted workplace democratization. Workers became involved in making decisions about the design of technology to resist being disadvantaged as management introduced information systems. PD has expanded to many other domains where technology is developed, such as health and education. Broadly speaking, participatory design encourages designers to find ways to work with the endusers of technologies to ensure that their needs and interests are addressed. A high priority is to foster a shared medium of communication, where workers/users can bring to bear their embodied expertise in realistic use situations. Often, participatory design utilizes playful approaches through workshops, activities or design games.

For example, as the news industry was becoming computerized in the early 1980s, Ehn and Kyng (1991) used cardboard mockups and prototypes in a kind of 'design game' with journalists, typographers and assistant editors at the Stockholm newspaper, Aftonbladet (p.175). An explicit aim of the project was to maintain typographic quality and to prevent the deskilling of jobs when equipment such as laser printers was introduced to newspaper production. Ehn and Kyng used cardboard and other familiar materials because they allow for 'hands-on experience' (p.177) and are 'understandable' in ways that descriptions of technology are not (p.172). They also help bring an element of fun to designing. With their example, Ehn and Kyng demonstrate that designers need to be 'play-makers' and to create design games that engage end-users and facilitate their participation in the design process (p.177). They also highlight that there is a role for using simple, familiar materials, such as paper and cardboard, alongside computer-based prototypes in realistic use settings, a point which we attempt to carry forward in our work.

\section{Probes}

Through the concept of probes, scholar-designers have critically explored the ways participants are involved in design research. Both cultural probes (an approach or method) and technological probes (artefacts or situations) serve to exemplify how probes value play. Boehner, Vertsi, Sengers and Dourish (2007) define cultural probes as 'a design-oriented way to acquire inspirational glimpses of communities targeted for design' $(2007,1077)$. Rather than trying to collect 'objective' data to be systematically analyzed in the design process, cultural probes are 'an approach to design that recognizes and embraces the notion that knowledge has limits. It's an approach that values uncertainty, play, exploration, and subjective interpretation as ways of dealing with those limits' (Gaver et al. 2004, 53-54). Cultural probes can include packages of materials and evocative and open-ended tasks which involve potential users or communities in the design process (Boehner et al. 2007). 
Technology probes, in contrast, use designed artefacts as a kind of evocative prototype (Hemmings et al. 2002). Langdale, Kay and Kummerfeld describe technology probes as 'an extension of the cultural probe methodology' $(2006,1002)$. The underlying emphasis is explicitly on playfulness, rather than data extraction from end-users who participate in design research. As an example of a technology probe, Gaver and colleagues describe the Plane Tracker as a cabinet with a TV screen and antenna that was deployed into homes impacted by air traffic noise. Radio signals from the planes passing overhead are used to display imagery from GoogleEarth with the actual flight paths of the planes being heard. Placing the plane tracker in homes was seen as a potentially 'richly evocative situation' (Michael and Gaver 2008, 8); we hope to create similarly evocative situations through our work. Building on previous scholarship, we see the potential to broaden traditional epistemological underpinnings of knowledge production in design by fostering playful opportunities for interaction with technological prototypes.

\section{Synthesis}

Designing to allow for play provides some key insights which contextualize our design of mock RFIDbased identification infrastructure. We bring these practice-influencing (and occasionally interacting) ${ }^{6}$ traditions to bear on our serious play and prototyping of RFID-based ID infrastructure. To varying extents, these traditions emphasize playfulness as a component both of everyday life and serious endeavours. We also acknowledge from our array of influences that there are sometimes challenges when bringing play into serious domains; it is difficult to predict how people will experience playful prototypes, and impossible to determine whether they will encourage participants to engage with the serious issues that motivate the design. We wish to stress that in our project, we want to explore how we instantiate democratic ideals through the design and implementation of technology. In our work, a broad interest in democracy has shaped our playful attempt to engage the public in ID scheme design.

\section{Motivations}

Influenced by Surveillance Studies, science and technology studies and playful design traditions, our motivations for designing mock ID infrastructure were to demonstrate basic functionality and engage playfully with the powerful social sorting implications of ID systems at a time of serious policy deliberations. In our introduction we highlighted the simple fact that backend databases are unseen by citizens who carry around ID cards. We aimed to create mock ID infrastructures for the purpose of making these databases more visible and demonstrating how ID schemes work.

ID infrastructures are complicated and even our policy makers cannot always immediately understand how the systems operate and what privacy risks are present in relation to personal information and the construction of databases. For example, during the public hearings for Bill 85: The Photocard Act, 2008, Ontario Member of Provincial Parliament (MPP) Giles Bisson clarified with the provincial Information and Privacy Commissioner that the RFID chip will always be readable if outside of a 'protective' sleeve:

Mr. Gilles Bisson: So it transmits once it's out?...

Dr. Ann Cavoukian: As the RFID standard chosen for this project [the chip on the card] will respond to any reader query, any pinging... (Ontario 2008)

Additionally, Cavoukian, Ontario's Information and Privacy Commissioner, emphasized the significance of the number on the RFID Gen 2 chip, the standard for EDL/EICs:

\footnotetext{
${ }^{6}$ See Hemmings et al. 2002, for example.
} 
Dr. Ann Cavoukian: So I just want to make this point: that just because it's a number and it doesn't have a name linked to it [on the chip] does not mean it cannot be linked to personally identifiable information [such as in a database]. (Ontario 2008)

In addition to basic functionality clarifications, the possibilities for database construction were not well understood by some members of provincial parliament during the public hearings when the legislation was under consideration. For example, MPP Mauro requested that a scenario be drawn for him of how the numbers transmitted from EDL/EIC RFID chips could be connected to personal information in a database. He entered into a dialogue with co-author Clement who made a submission to the public hearing:

Mr. Bill Mauro: But in practical terms, how would somebody, if they had my number somehow, know that it was associated with me, unless they were able to get into the database that it links to?

Dr. Andrew Clement: If you take your card out, let's say, when you're buying something or you have to show it, like at the post office ... then they can read the number off your card and they can take a photograph of you.

Mr. Bill Mauro: They can read the number off my card?

Dr. Andrew Clement: The reading of the number on the card can be done at a range of 30 feet. So if I had the equipment, I could bring it into this room and read the card numbers of all of the cards of everybody in this room that were not protected.

(Ontario 2008)

The idea that a shadow database could be constructed in addition to official governmental databases did not seem immediately evident to MPP Mauro, based on his question about 'the' [singular] database. It is our research assumption that what was illustrated with words in the Standing Committee can be more compellingly demonstrated with realistic equipment and the use and experiencing of the infrastructure. In the next section, we describe our prototyping activities as we provide a timeline of the policy process for EDLs/EICs in Ontario.

\section{Prototyping mock RFID-based identification infrastructure}

Digital media designers often refer to two types of prototyping: low fidelity and high fidelity. Our design of a mock RFID-based identification infrastructure drew upon both of these forms during the period in Ontario when the 'black box' of ID infrastructure was somewhat open as legislation to introduce EDLs and EICs was considered. ${ }^{7}$ We began with paper prototyping, using low fidelity materials that were similar to ID cards. Later, during the production of RFID-based ID infrastructure probes, we utilized technologies similar to those that are present in a governmental ID infrastructure. In this manner, our work was a high fidelity instantiation of an ID probe and prototype. The following table presents the policy development timeline in conjunction with our design and research activities (see Table 1). In the subsequent sub-sections our paper-based ID prototypes and high fidelity RFID-based ID probes are described in greater detail.

\footnotetext{
7 In the Ontario political system, a bill must go through 3 readings in the legislature. It must be voted on by the members of provincial parliament (MPPs) and receive Royal Assent to pass into law. Bill 85 was officially initiated on June 3, 2008 with its first reading and it received Royal Assent on November 27, 2008. The period where public participation was a possibility in the Bill was after the second reading when it was sent to the Standing Committee on General Government. The Committee called for public hearings on the Bill. After the Bill passed, the regulations were available for public comment.
} 


\begin{tabular}{|c|c|c|}
\hline $\begin{array}{l}\text { EDL policy } \\
\text { development }\end{array}$ & Design and research activities & $\begin{array}{l}\text { Design } \\
\text { phase }\end{array}$ \\
\hline $\begin{array}{l}\text { Bill } 85 \text { policy making } \\
\text { process: }\end{array}$ & $\begin{array}{l}\text { - The research team demonstrates paper-based ID } \\
\text { prototypes as conference name badges for the New } \\
\text { Sciences of Protection: Designing Safe Living } \\
\text { conference at Lancaster University, July 10-12 } 2008 \\
\text { - The research team co-organized a Public } \\
\text { Information Forum on Ontario's proposed } \\
\text { Enhanced Driver's Licence with the Information and } \\
\text { Privacy Commissioner of Ontario, Ann Cavoukian, } \\
\text { held July 16, } 2008\end{array}$ & $\begin{array}{l}\text { Paper } \\
\text { prototyping }\end{array}$ \\
\hline $\begin{array}{l}\text { Bill } 85 \text { policy making } \\
\text { process: } \\
\text { - June } 3-11,2008- \\
\text { First and Second } \\
\text { Reading and } \\
\text { debates of Bill } 85 \\
\text { - October 20, } 27 \text { and } \\
28 \text { - Bill } 85 \text { is at } \\
\text { the Standing } \\
\text { Committee on } \\
\text { General } \\
\text { Government } \\
\text { November 5-18, } \\
\text { 2008 - Third } \\
\text { Reading and } \\
\text { debates of Bill } 85 \\
\text { November 27, } \\
\text { 2008 - Bill } 85 \\
\text { receives Royal } \\
\text { Assent } \\
\text { December 5, 2008 } \\
\text { to January 5, 2009 } \\
\text { - Regulations for } \\
\text { Bill } 85 \text { are } \\
\text { available for public } \\
\text { comment } \\
\end{array}$ & $\begin{array}{l}\text { - Researchers develop the Canadian Identity Forum } \\
\text { website for making information about ID schemes } \\
\text { publically available. see: } \text { http://IDforum.ca } \\
\text { - Researchers follow the Hansard online and EDL } \\
\text { policy development } \\
\text { - Researcher Clement makes a statement at the public } \\
\text { hearing on security and privacy risks with EDLs } \\
\text { - Researchers take field notes at all publically } \\
\text { accessible committee events }\end{array}$ & $\begin{array}{l}\text { RFID-based } \\
\text { ID } \\
\text { infrastructure } \\
\text { prototypes } \\
\text { begin in } \\
\text { December } \\
2008\end{array}$ \\
\hline
\end{tabular}




\begin{tabular}{|c|c|c|}
\hline $\begin{array}{l}\text { EDL policy } \\
\text { development }\end{array}$ & Design and research activities & $\begin{array}{l}\text { Design } \\
\text { phase }\end{array}$ \\
\hline $\begin{array}{l}\text { Post Bill 85: } \\
\text { - June 1, 2009 - } \\
\text { Western } \\
\text { Hemisphere Travel } \\
\text { Initiative (WHTI) } \\
\text { comes into effect } \\
\text { for US land } \\
\text { borders }\end{array}$ & $\begin{array}{l}\text { - Identity Research Roundtable held at the Identity, } \\
\text { Privacy and Security Institute at the University of } \\
\text { Toronto, March 6, 2009. First demonstration of } \\
\text { RFID capabilities. } \\
\text { - Surveillance and Empowerment research workshop } \\
\text { at Vanderbilt University, March 20-22, } 2009 \text { in } \\
\text { Nashville TN. First demonstration of combination of } \\
\text { mock ID cards with RFID capabilities. RFID } \\
\text { technology does not work. } \\
\text { - In co-operation with the Canadian Civil Liberties } \\
\text { Association, the Consumers Council of Canada, the } \\
\text { Council of Canadians, and the International Civil } \\
\text { Liberties Monitoring Group we organize the } \\
\text { National public forum on 'enhanced' drivers } \\
\text { licences, privacy and state surveillance under the } \\
\text { new Canada-U.S. border regime held March } 24 \text {, } \\
\text { 2009 in Ottawa, Ontario. Demonstration of RFID } \\
\text { capabilities. } \\
\text { IPSI Research Symposium was held on May 6, } 2009 . \\
\text { Demonstration of combination of mock ID cards } \\
\text { with RFID capabilities. RFID technology works this } \\
\text { time. } \\
\text { KMDI at 13: Ensuring Privacy and Security at the } \\
\text { Knowledge Design Media Institute on May 7, } 2009 \text {. } \\
\text { Demonstration of RFID capabilities. } \\
\text { Computers Freedom and Privacy (CFP) conference, } \\
\text { June 1-4, 2009. RFID demo and panel session on } \\
\text { Enhanced Drivers Licences, Washington DC. } \\
\text { Demonstration of combination of mock ID cards } \\
\text { with RFID capabilities. } \\
\text { - Global Surveillance Society? Conference, April } 13 \text { - } \\
\text { with RFID capabilities. }\end{array}$ & $\begin{array}{l}\text { RFID-based } \\
\text { ID } \\
\text { infrastructure } \\
\text { prototypes } \\
\text { refined and } \\
\text { demonstrated }\end{array}$ \\
\hline
\end{tabular}

Table 1: Bill 85, The Photocard Act, 2008 (Ontario) and design and research timeline

\section{Paper prototyping}

Developing design probes of identification infrastructure was an iterative process. The first phase was a paper prototyping exercise. In the summer of 2008, team member Clement was scheduled to attend the New Sciences of Protection: Designing Safe Living conference at Lancaster University. He volunteered to create paper-based ID badges for the conference which were intended to draw upon trends in biometric and secure ID documents from around the world. The ID badges were given the moniker SafeTBioID ${ }^{\mathrm{TM}}$ and stated to be produced by the fictitious corporation, Total Transparency Solutions ${ }^{\mathrm{TM}}$ (see Figure 3).

Total Transparency Solutions ${ }^{\mathrm{TM}}$ was staffed by Clement's research team and the resultant badges featured names, photos, mock DNA codes, biometric identifiers, machine readable zones, mock RFID chips and security threat assessment levels. The ID badges were designed in a word processing program and printed on a standard colour printer. 
With the paper prototypes in hand, conference attendees were informed, in a playful manner, that biometric and sociometric data from national health, public safety and security services was coded into the name badge. The badge prominently displayed risk factors as well as an aggregated threat level based on the personal data collected. In the top right-hand corner of Figure 3, 'ILO' for example corresponds to personal risks of insomnia, lung cancer and obesity. Positioning themselves as stern but benign authorities, conference organizers announced that to avoid incurring personal harm, attendees with these codes would be prohibited from the following activities: drinking coffee, smoking, and eating dessert, respectively. Signs in the food area provided reminders. Public risk factors, i.e. where an individual was a risk to others, appeared in the coloured band in the middle of the card. The code 'FHLO' indicates that this individual presented a public risk of flatulence, hijacking, lung cancer and obesity. These latter two factors appear as public risks since the additional health care costs from these disorders would be borne by taxpayers. The red band in the middle of this badge denotes a high risk conference attendee. The range of threat scores, from 0 to 350, roughly corresponds to the range used by US Customs and Border Patrol, to rate the threat levels of people entering the US. No more than 2 high risk attendees were to meet on their own.

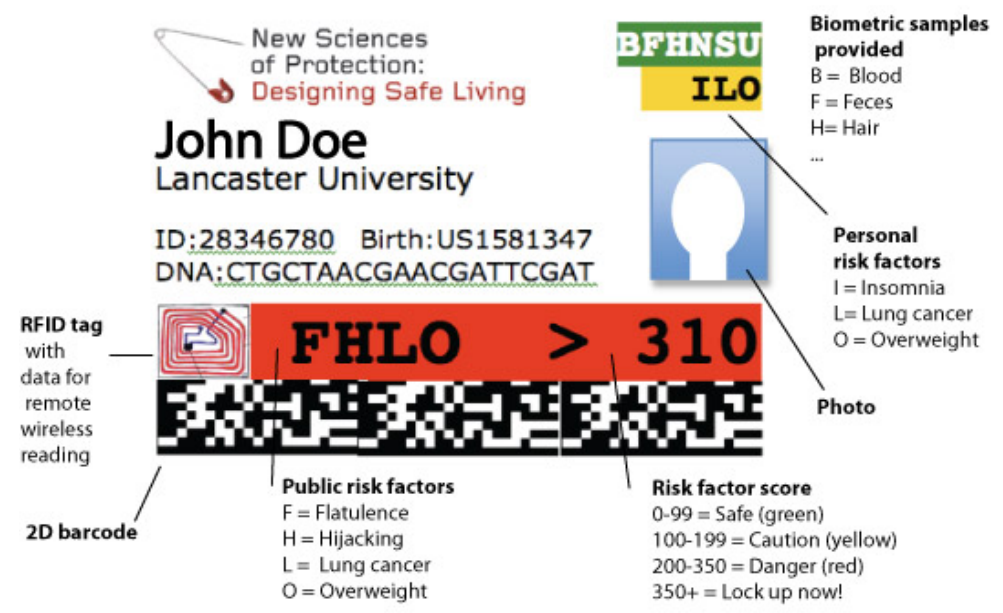

Figure 3: Mock ID cards for New Sciences of Protection: Designing Safe Living

Adhering to the conference rules was encouraged on the basis of (theoretical) remote tracking and surveillance to be carried out using various means. For example, video cameras and the RFID chips claimed to be present in the card would inform the organizers that an insomniac was too near the coffee table. Similarly, bio-sensors in the washrooms that could detect caffeine and other dangerous substances in urine would alert officials to infractions of the safe conferencing rules. This paper-based mock biometric ID infrastructure was well received by conference attendees and informed our subsequent research with RFID-based ID prototypes. See Figure 4 for a photo of speakers on the conference surveillance panel showing their name badges.

\section{RFID-based ID infrastructure probes}

Based on the success of the SafeTBioID ${ }^{\mathrm{TM}}$ paper prototypes, the Total Transparency Solutions ${ }^{\mathrm{TM}}$ research team became interested in prototyping and extending the model to critically probe government introduction of RFID technologies into ID infrastructure during the time of serious policy deliberations on this matter. As explained previously, the research team followed the Ontario government's initiative to introduce optional, RFID enabled driver's licences and identity cards. Within this context of an imminent policy program, the team decided to experiment with functional prototypes, using materials and equipment much like the government would use to roll out enhanced identification schemes. 


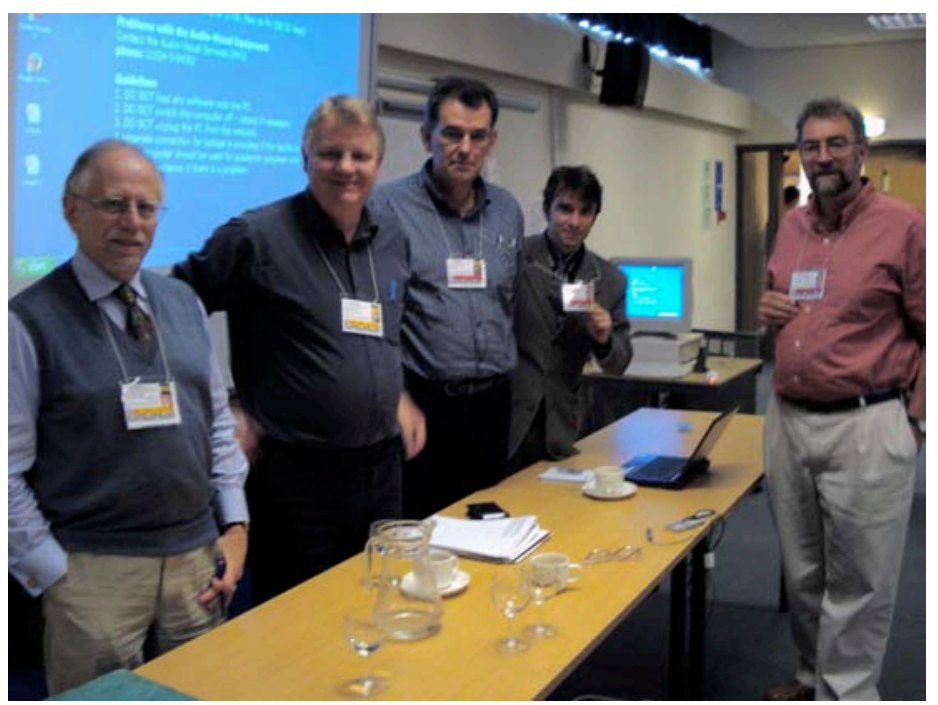

Figure 4: Speakers on the surveillance panel at the New Sciences of Protection conference showing their mock ID badges. (From left: Charles Raab, Clive Norris, Lucas Introna, David Murakami Wood, and Andrew

Clement. Photographer unknown)

Work to develop an RFID based ID infrastructure began in earnest in December 2008 with the hiring of Tichine, an engineering graduate student, to build a system to test and use RFID ID infrastructures. His initial tasks were to test the read range of RFID cards, to demonstrate 'killing' the cards and cloning, and also to test the effectiveness of the protective sleeves (Faraday cages) which were to be issued with RFID cards. These tasks were carried out using the equipment described in Table 2 in December 2008. Notes and progress were recorded in a team wiki.

\begin{tabular}{|l|l|}
\hline Item and function & \\
\hline Antenna: used to read RFID cards at \\
long range (up to 10m)
\end{tabular}

Table 2: RFID-based ID infrastructure prototyping equipment

In reference to Table 2, it is noteworthy that the equipment utilized was expensive to obtain and there 
were delays for the researchers to be able to begin their work. The equipment cost approximately $\$ 10,000$ (USD). The research team experienced a lengthy delay between ordering and obtaining equipment, in part attributable to the high demand at that time for deployment of this type of equipment at US land border crossings.

By late February, 2009, Tichine had modified the Framework for IF $61^{8}$ demonstration software to create an $m x n$ grid to display which RFID cards had been read. The first opportunity to test this software publically came on March 6, 2009, with an IPSI-sponsored Identity Research Roundtable held at the University of Toronto. The research team provided each person attending the roundtable with their own unique RFID card upon their arrival. As attendees entered the roundtable room, the corresponding cell on the matrix lit up on the screen (see Figure 5). While they expressed interest in this mock RFID-based ID software, attendees found it difficult to understand, in part because of the vagaries of the read distance and the lack of immediately obvious correspondence between their card and the computer display. This prompted further iterations of the prototype.

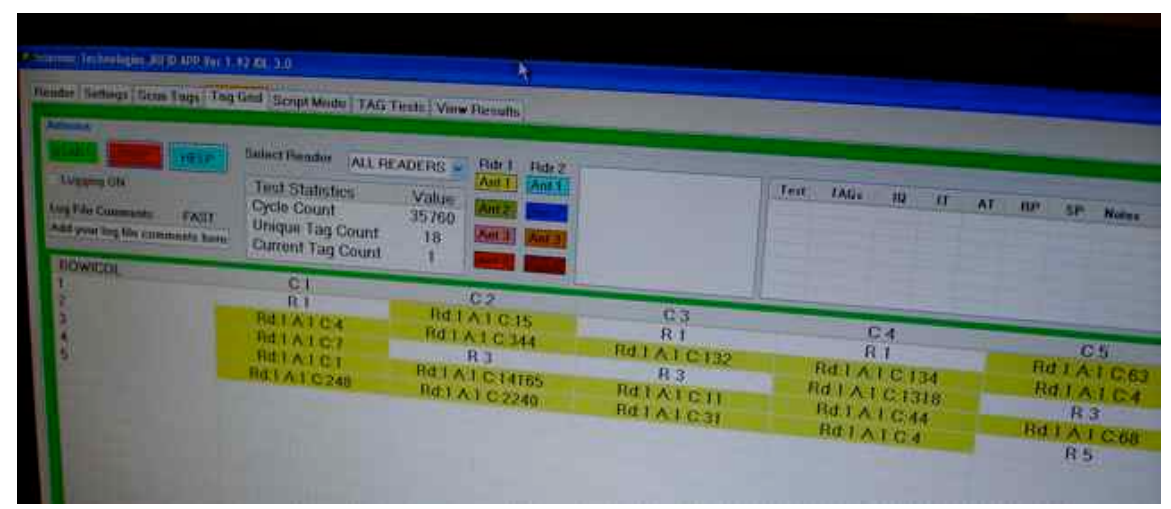

Figure 5: RFID-based ID software prototype (v1)

On a very tight timeline, we modified the prototype to link the RFID numbers more visibly to the mock ID cards created earlier. With the hope of influencing provincial policy development outside of Ontario, the "National public forum on "enhanced" drivers licences, privacy and state surveillance under the new Canada-U.S. border regime' was scheduled in Ottawa, Canada on March 24, 2009. The event was coorganized by: The Canadian Civil Liberties Association, the Consumers Council of Canada, the Council of Canadians, the Information Policy Research Program of the Faculty of Information - University of Toronto and the International Civil Liberties Monitoring Group. As the Faculty of Information and University of Toronto representatives, one of our main contributions was to allow attendees to experience an RFID-based ID infrastructure. The research team determined that in order to make the experience of interacting with RFID-based ID infrastructure more meaningful, the prototype required significant modifications. Ideas generated and implemented in version 2 (see Figure 6) included:

- display names of card holders instead of tag numbers

- use previously stored personal information linked by the unique tag numbers on the RFID cards to visibly 'welcome' people as they show up and enter a space

- paint cells on the display matrix according to threat levels (green, yellow, red)

\footnotetext{
${ }^{8}$ Framework for IF61 is the code made available for developers to use in conjunction with their Intermec ${ }^{\mathrm{TM}}$ IF61 Enterprise Reader equipment.
} 
- generate an overall 'threat' level for the room, aggregated from the individual public risks scores of the recently read cards. The five level colour scheme was based directly on that currently in use by the U.S. Department of Homeland Security. ${ }^{9}$

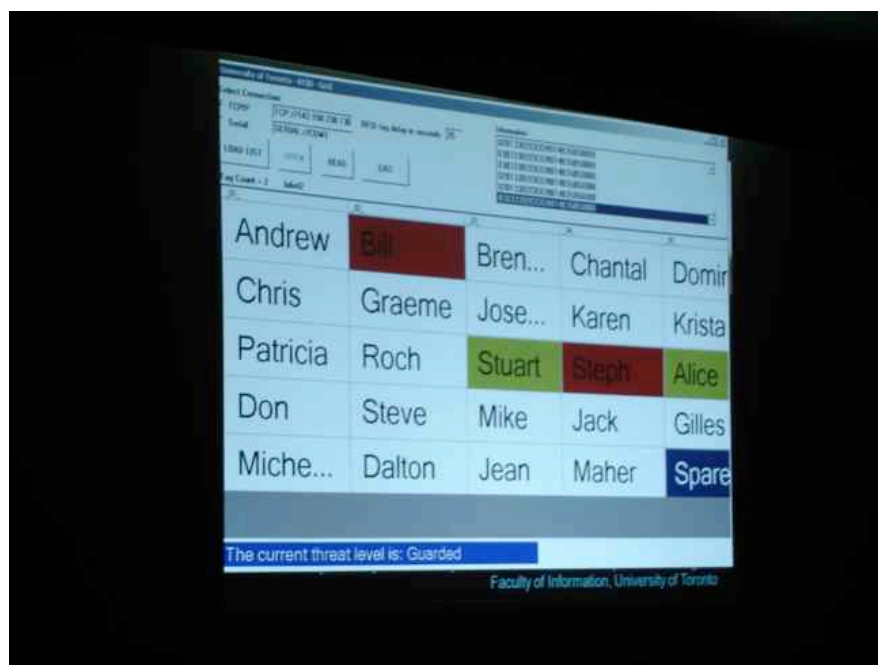

Figure 6: RFID-based ID software prototype (v2)

Still working extensively with the framework code, version 2 of the prototype successfully allowed us to demonstrate how tracking of an individual with an RFID-equipped driver's license could be carried out (i.e. to record and display who entered a room). Additionally, the newer version of the grid software with names and colours successfully allowed us to demonstrate how information stored in databases could be used to make social sorting and threat assessment decisions.

Further additions to the prototype were however envisioned and implemented for version 3 (see Figures 1 and 7). In May 2009, two events were scheduled that offered further opportunities to deploy the prototype in a public setting. First, the IPSI Research Symposium was held on May 6, 2009 and Clement was invited to deliver a lecture to the Knowledge Design Media Institute on May 7, 2009 titled: KMDI at 13: Ensuring Privacy and Security.

The IPSI Research Symposium included high profile individuals within the privacy community such as Bruce Schneier as keynote speaker, and Ann Cavoukian, Ontario's Information and Privacy Commissioner. For this event, the prototype was refined in a number of ways. First, a loop was introduced to the software, so that the tags of people in the room would be read periodically. Once detected, the tag information was stored and retained between scans; if it was not detected in the subsequent scan, the tag was removed from the display. Previously, when someone exited the room the system was not able to represent it. Secondly, a display window on the right side of the screen was created to provide extended biographical information about the individuals whose tags were detected via the RFID ID cards, as part of the mock infrastructure. In this manner, the system functioned like an attendance system with the ability to retrieve and display information from a database using RFID ID tags to link with previously obtained information about symposium attendees.

Schneier's information displayed in Figure 7 below was hyperlinked in our database to the profile information screen shown in Figure 1.

\footnotetext{
9 The DHS scheme is: green: LOW - low risk of terrorist attacks; blue - GUARDED - general risk of terrorist attacks; yellow ELEVATED - significant risk of terrorist attacks; orange - HIGH - high risk of terrorist attacks; red - SEVERE - severe risk of terrorist attacks. See: http://www.ncbi.nlm.nih.gov/bookshelf/br.fcgi?book=hserta\&part=A139137\&id=A139561
} 


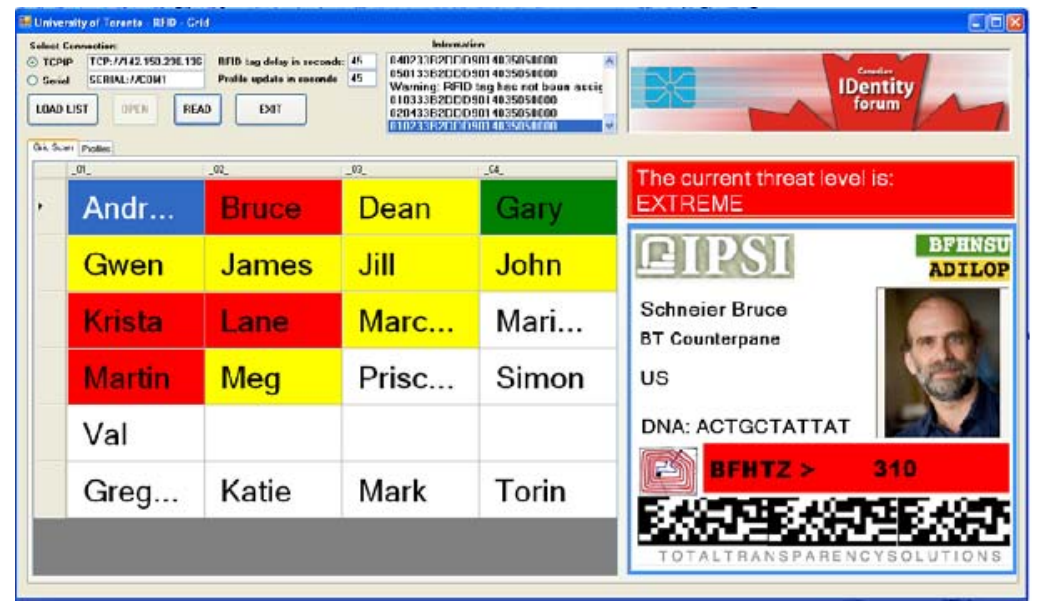

Figure 7: RFID-based ID software prototype (v3)

\section{Implementation reflections}

At present, we have deployed provocative name badges/RFID card prototypes at eight events of varying size, purpose, audience and 'publicness'. We estimate that well over 300 individuals have experienced the Total Transparency Solutions ${ }^{\mathrm{TM}}$ mock ID scheme themselves, in the sense of wearing one of our ID cards. Over the course of these events we have iteratively developed a functional RFID-based ID scheme, one that closely mimics technical features of government-developed ID schemes. We have refined the scheme through engagement with ID subjects in the context of an on-going policy discourse. We can claim some success in informing people better about what such schemes may mean for them, as well as contributing to a public critique of the security and privacy risks of RFID-based ID technologies. We are also acutely aware of the limitations of our research to this point, as well as the need to go much further.

So far we have found it difficult to assess reliably what our ID subjects make of the mock ID scheme. Giving priority to getting all the various hardware and software components to work together properly has inexorably deflected attention away from careful empirical evaluation of the results. However, we do have considerable anecdotal evidence to draw upon. It is clear that it is hard for many people to see the point of the exercise and how the RFID cards work. In part this is because their RFID cards do not get read reliably. The technical characteristics of relative separation and orientation of card and antenna, interference from other sources, and signal blockage from intervening materials (notably human bodies) impair the read capabilities, leaving people puzzled by the lack of effect. While this helps point out the contingency and fallibility of these high-tech devices, it also undermines the claim we make that this particular RFID technology (EPC Gen 2) is designed for surreptitious tracking at distances up to 10 metres. Laboratory tests under ideal conditions show a read range of up to 50 metres (Koscher et al. 2008) but in the 'real world' setting of live public events, subjects appear to have to willingly collaborate with the researchers to produce any results. Also, we faced many of the usual pitfalls of demonstrating experimental computer systems - software glitches, inscrutable interfaces and bumbling, inexperienced operators (i.e. us). While we designed the ID cards to be as (humanly) readable as possible, there is a great deal of obscure information on them, making them difficult to decipher. Most of these obstacles can be overcome through further refinements.

On the other hand, we have found encouragement in the abundant indications of appreciation, expressed in smiles, personal comments, over-heard conversation snippets and playful reactions, to assure us that many people already enjoy this form of playing with ID, and 'get' some of the policy implications. This has been an important factor in motivating us to refine the scheme and try it out at the next opportunity. 
However, even if all our participants play along with us, we still face daunting challenges. Indeed, achieving engagement through irony and play may even undermine our goals for influencing policy development. Showing the fun and contingent character of biometric, RFID based ID schemes might as easily legitimate as undermine them. Trying out mock ID cards helps familiarize people with the techniques and can obscure the sharp edges when the intentions are less benign.

Even if our demonstrations do help people become aware of the issues at stake and more willing to become involved in the policy debate, it is very difficult for them to translate this into effective action. There are very few ways for people to make their voices heard in conventional public policy discussions, even when the issues are more familiar and the potential consequences immediate. This of course is a widespread problem, often referred to as the 'democratic deficit'. ${ }^{10}$

We encountered some of these systemic obstacles in our own attempts to contribute to the policy debate. Timing is often crucial when there is a perceptible policy window of opportunity (Kingdon 1984). In the case of the EDL, we were able to respond quickly to the Ontario Government's announcement in June 2008 (Ontario 2008) that it would be introducing Bill 85, and convened a public information forum with the provincial Information and Privacy Commissioner soon after the Bill received first and second reading. We also set up a website, www.IDforum.ca to make available background information and to help compensate for an initial lack of government-provided materials. But it took another seven months before we could demonstrate the capabilities of RFID based ID, and by that time the legislation had passed through major stages of the policy-making process. Where it might have been most effective was in the public hearings held by the Legislative Committee dealing with Bill 85 , since its members evidently had questions. Potentially, a demonstration could also have helped to stimulate more media coverage, highlighting the privacy and security risks, which may have made it harder for the Government to push through the legislation. On the other hand, it appears that the Government had committed itself to this course of action many months earlier, and was going to proceed regardless of the opposition or public concerns. We do note that several other provinces, Saskatchewan, Prince Edward Island and Nova Scotia, which had been considering developing their own EDLs, decided not to pursue them after all. They mainly cited cost and privacy considerations for getting cold feet, concerns to which we and civil society organizations had been pointing.

\section{Conclusion}

The policy development phase for ID infrastructures is ideally a period of ambiguity and openness, where experiential insights can be brought to bear on decision-making. Throughout this paper, we have demonstrated how our playful practice-based design activities are interwoven with fieldwork, advocacy, and public engagement. We situate our prototyping activities within the broad context of playful influences and were guided by participatory design and probe methods while implementing our designs. These efforts are part of our broader research agenda, which looks at the affordances and challenges of emerging technologies for institutional identification practices.

Our work continues to critically question the effectiveness of 'enhancing' ID infrastructures with technologies such as RFID chip and biometrics. In the near future we hope to integrate an open source face detection and tracking algorithm that will help demonstrate in real-time some of the capacities of digital signal processing and video analytics. We also plan to prototype a 'proportionate ID' wallet, a digital ID device that reveals the minimum amount of identifying information for conducting transactions. While recognizing the drawbacks of over-rationalizing the use of probe methods (Gaver et al. 2004), we

\footnotetext{
10 "A democratic deficit refers to "a substantial decline in" citizens" "confidence in their democratic practices and institutions" (Cross 2005, p.ix).
} 
wish to more systematically explore the ways that participants respond to, engage with, or dismiss the technologies we prototype.

Understanding ID infrastructures, including RFID capabilities and the ways backend systems are designed, maintained, and cross-linked, is essential for more nuanced insights into the associated potential surveillance practices and resulting privacy risks. Our mock ID infrastructure is an attempt to contribute to the theoretical and policy contexts in which these emerging technologies are being considered and deployed. Further, it is an explicit attempt to playfully engage citizens in a manner which encourages serious consideration of the ways in which ID schemes and infrastructures might affect them individually and collectively as members of our society.

\section{Acknowledgements}

This work was carried out with the support of the Social Science and Humanities Research Council of Canada (SSHRC) (grant \# 484803) for the Performing Identities Project. We wish to thank project collaborators who assisted in organizing the numerous events where our RFID-based ID infrastructure was deployed as well as the participants at these events. We also thank the Faculty of Information, Knowledge Media Design Institute (KMDI) and Identity, Privacy and Security Institute (IPSI) at the University of Toronto. IPSI purchased the RFID equipment we used and funded the software development. Gale Moore, Brian Cantwell Smith and others provided helpful feedback on the draft of this paper which greatly enhanced our work. Finally, author Smith offers thanks to SSHRC for support of her doctoral studies.

\section{References}

Albrechtslund, Anders and Lynsey Dubbeld. 2005. The Plays and Arts of Surveillance: Studying Surveillance as Entertainment. Surveillance \& Society 3 (2/3): 216-221

Allen, Jan, Kirsty Robertson and Sarah E.K. Smith, eds. 2010. Sorting Daemons: Art, Surveillance Regimes and Social Control Kingston, ON: Agnes Etherington Art Centre.

Bjerknes, Gro and Tone Bratteteig. 1995. User Participation and Democracy: A Discussion of Scandinavian Research on System Development. Scandinavian Journal of Information Systems 7 (1):73-78.

Boehner, Kirsten, Janet Vertesi, Phoebe Sengers and Paul Dourish. 2007. How HCI interprets the probes. Paper read at CHI, at San Jose, CA.

Bowker, Geoffrey C. and Susan Leigh Star. 1999. Sorting things out: classification and its consequences, Inside technology. Cambridge, MA.: MIT Press.

Brown, Bill. the Surveillance Camera Players . . 1996 [cited 29 Oct 2010]. Available from http://www.notbored.org/scp.html.

Brown, Mark B. 2001. The Civic Shaping of Technology: California's Electric Vehicle Program. Science Technology \& Human Values 26 (1): 56-81.

Carter, Michael. Guerilla Programming of Video Surveillance Equipment 1995 [cited 29 Oct 2010. Available from http://www.notbored.org/gpvse.html.

Clement, Andrew and Peter van den Besselaar. 1993. A retrospective look at PD projects. Communications of the ACM 36 (3): 29-37

Cross, William. 2005. Foreward. In D. Barney, Canadian democratic audit: Communication technology. Vancouver: UBC Press.

Ehn, Pelle and Morten Kyng. 1991. Cardboard computers: Mocking it up or hands on the future. In Design at work: cooperative design of computer systems, edited by J. M. Greenbaum and M. Kyng. Hillsdale, NJ.: L. Erlbaum Associates.

Friedmann, Batya and Helen Nissenbaum. 1996. Bias in computer systems. ACM transactions on information systems 14 (3): 330-347.

Gaver, William W., Andrew Boucher, Sarah Pennington and Brendan Walker. 2004. Cultural probes and the value of uncertainty. Interactions 11 (5): 53-56.

Hemmings, Terry, Andy Crabtree, Tom Rodden, Karen Clarke, and Mark Rouncefield. 2002. Probing the Probes. Paper read at Participatory Design Conference, 23-25 June, at Malmo Sweden.

Introna, Lucas D. and David Wood. 2004. Picturing Algorithmic Surveillance: The politics of facial recognition systems. Surveillance and Society 2 (2/3): 177-198.

Kingdon, John W. 1984. Agendas, alternatives, and public policies. Boston: Little Brown.

Koscher, K., A. Juels, T. Kohno and V. Brajkovic. EPC RFID Tags in Security Applications: Passport Cards, Enhanced Drivers Licenses, and Beyond 2008 [cited 28 April 2009]. Available from http://www.rsa.com/rsalabs/staff/bios/ajuels/publications/EPC RFID/Gen2authentication--22Oct08a.pdf.

Langdale, Geoff, Judy Kay and Bob Kummerfeld. 2006. Using an intergenerational communications system as a 'light-weight' technology probe. Paper read at CHI '06 at Montreal, Canada.

Lego. Lego Serious Play n.d. [cited 29 Oct 2010]. Available from http://www.seriousplay.com/.

Lloyd, Martin. 2003. The passport: The history of man's most travelled document. Phoenix: Sutton Publishing Ltd.

Lyon, David. 2009. Identiftying citizens: ID cards as surveillance. Cambridge: Polity. 
McPhail, Brenda, Krista Boa, Joseph Ferenbok, Karen Louise Smith and Andrew Clement. 2009. Identity, privacy and security challenges with Ontario's enhanced driver's licence. IEEE Explore.

Michael, Mike, and William Gaver. 2008. Home beyond home: Dwelling with threshold devices. Space and culture 12, August 2009:359-370.

Ontario. Standing Committee on General Government [Submissions to the public hearing on Bill 85: The Photocard Act] 2008 [cited 05 March 2010]. Available from http://www.ontla.on.ca/committee-proceedings/transcripts/files html/20-OCT2008 G011.htm\#P88 6258.

Orvis, Karin, Jennifer Moore, James Belanich, Jennifer Murphy and Daniel Horn. 2010 Are soldiers gamers? Videogame usage among soldiers and implications for the effective use of serious videogames for military training. Military psychology 22 (2): 143-157.

Pinch, Trevor and Wiebe Bijker. 1984. The Social Construction of Facts and Artefacts: Or How the Sociology of Science and the Sociology of Technology might Benefit Each Other. Social Studies of Science 14: 388 - 441.

Ritterfield, Ute, Michael Cody and Peter Vorderer, eds. 2009. Serious games: mechanisms and effects. New York: Routledge.

Samuel, Alexandra Whitney. 2004. Hacktivism and the future of political participation, Political Science, Dissertation Abstracts International. (UMI: AAT 3149592). Harvard, Boston.

Schneier, Bruce. 2003. Beyond fear: thinking sensibly about security in an uncertain world. New York: Copernicus Books.

—. IPSI Welcome and Bruce Schneier Keynote. 2009 [cited 14 March 2010]. Available from: http://hosting.epresence.tv/KMDI/1/watch/511.aspx.

Schrage, Michael. 2000. Serious play: how the world's best companies simulate to innovate. Boston, MA.: Harvard Business School Press.

Star, Susan Leigh. 2002. Infrastructure and ethnographic practice: Working on the fringes. Scandinavian Journal of Information Systems 14 (2): 107-122.

Summerton, Jane. 2004. Do Electrons Have Politics? Constructing User Identities in Swedish Electricity. Science Technology Human Values 29 (4): 486-511.

Torpey, J. 2000. The invention of the passport: Surveillance citizenship and the state. Cambridge: Cambridge University Press.

Winner, Langdon. 1993. Upon Opening the Black Box and Finding It Empty: Social Constructivism and the Philosophy of Technology Science Technology, \& Human Values 18 (3): 362-379. 